\section{Purification of Chlorophyll c from Sargassum flavicans}

ChLOROPHYLL $c$ occurs in many types of marine alga $\Theta^{I}$. Little is known of its chemistry or function, and methods used for its quantitative estimation are indirect ${ }^{2}$. The present work describes a method for the crystallization of chlorophyll $c$ from the marine alga, Sargassum flavicans.

Fresh Sargassum weed was macerated several times with acetone/methanol $(50: 50, \mathrm{v} / \mathrm{v})$. The pigment extract was filtered, and the pigments were trans. ferred to ethyl ether by adding an equal volume of ether and washing with 5 volumes of 10 per cent sodium chloride. The ether extract was concentrated to a small volume by evaporation under a stream of air. Chlorophyll $c$ was separated from chlorophyll $a$ and carotenoids by chromatographing the ethyl ether extract on cellulose powder columns using 0.5 per cent $(\mathrm{v} / \mathrm{v}) n$-propanol in light petroleum $\left(60^{\circ}-80^{\circ}\right)$ as developing solvent ${ }^{3}$. Chlorophyll $c$ remained as a light green zone at the top of the column. The zones of cellulose containing adsorbed chlorophyll $c$ were collected and repacked into a fresh column, and the chlorophyll $c$ was eluted with 5 per cent $(\mathrm{v} / \mathrm{v})$ methanol in ethyl ether.

The extinction coefficient of this material (chlorophyll $c$, stage 1) at $630 \mathrm{~m} \mu$ in acetone was $2.24 \mathrm{l}$./gm, $\mathrm{cm}$. Although free from other pigments, the chlorophyll $c$ was heavily contaminated with phospholipid. This was shown by chromatographing an aliquot on paper impregnated with silicic acid according to the method of Marinetti and Stotz ${ }^{4}$. Six lipid fractions were present, and total phosphorus determinations gave values of $1.18 \mathrm{mgm}$. phosphorus/100 mgm. chlorophyll $c$.

Chlorophyll $c$ (stage 1) was partially freed from lipid by chromatography on columns of silicic acid which had been mixed with 'Hyflo Supercel' $(2 \cdot 5: 1$, $\mathrm{w} / \mathrm{w}$ ) in chloroform. Chlorophyll $c$ was eluted with 5 per cent methanol in chloroform (stage 2). The extinction coofficient of this material in acotone at $630 \mathrm{~m} \mu$ was $9.91 \mathrm{l} . / \mathrm{gm}$. cm. Four lipid fractions were removed, and total phosphorus determinations gave values of $0.1 \mathrm{mgm}$. phosphorus $/ 100 \mathrm{mgm}$. chlorophyll $c$.

The final purification of chlorophyll $c$ was achievod by chromatography on columns of neutral aluminium oxide. Chlorophyll $c$ was strongly adsorbed at the top of the column. Traces of carotenoid and one lipid fraction were removed with methanol/chloroform $(9: 1, v / v)$. The remaining lipid fraction was removed with ethanol/chloroform/water, $5: 2: 1$ $(\mathrm{v} / \mathrm{v} / \mathrm{v})$. Chlorophyll $c$ was finally eluted with ethanol/ chloroform/water, $5: 2: 2.5(\mathrm{v} / \mathrm{v} / \mathrm{v})$. The emeraldgreen solution (stage 3) was concentrated by evaporation under nitrogen, until the solution changed colour and a deep copper-red precipitate appeared.

Crystallization was achieved by redissolving the precipitate in the minimum quantity of ethanol, adding water to about $5-10$ per cent, and leaving in the dark at room temperature. After $24 \mathrm{hr}$., reddish. black crystals had separated from the mother liquor. Large crystals $(100 \mu)$ essumed the habit of parallelsided plates (Fig. 1) and minute crystals $(3-5 \mu)$ appeared as hexagonal platelets.

The extinction coefficient of chlorophyll $c$ (stage 3) in 100 per cent acetone at $630 \mathrm{~m} \mu$ was $15 \cdot 81 . / \mathrm{gm}$. cm., and the absorption maxima in acetone were at 628 , 580 , and $442 \mathrm{mu}$. Magnesium estimations (atomic absorption spectroscopy) gave a mean value of $2 \cdot 38$

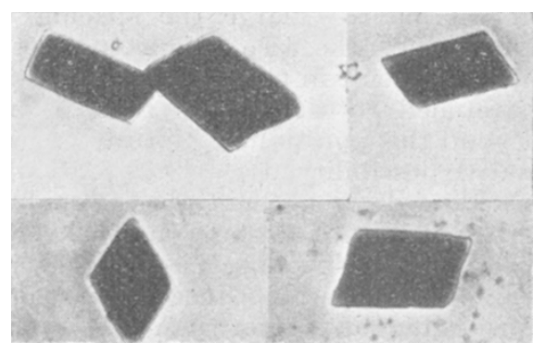

Fig. 1. Chlorophyll $c$ crystallized from aqueous ethanol

mgm. magnesium/100 mgm. chlorophyll $c$ (range 2 13 $2 \cdot 60)$. Assuming ono magnesium atom per molecule, and using the mean value of $2 \cdot 38$ per cent magnesium, the molecular weight of chlorophyll $c$ would be 1,020 . This is the same order of magnitude as chlorophyll $a$ (893) and chlorophyll $b$ (907). Granick ${ }^{5}$ suggested that chlorophyll $c$ was a phytol-free chlorophyll (mol. wt. about 600) on the basis of its low hydrochloric acid number. If phytol is indeed absent, then chlorophyll $c$ must possess alternative groups attached to the chlorophyll nucleus.

Detailed descriptions of the methods used and the properties of the crystalline chlorophyll $c$ will be published elsewhere.

I thank Dr. B. G. Davey, Faculty of Agriculture, University of Sydney, for the magnesium determinations.

\section{S. W. JEFFREY}

\section{C.S.I.R.O. Marine Laboratory,} Cronulla, Sydney.

${ }^{1}$ Strain, H. H., Manual of Phycology, edit. by Smith, G. M., 243 (Chronica Botanica Co., 1951)

sichards, F. A., and Thompson, T. G., J. Mar. Res., 11, 156 (1952). - Strain, H. H., Chloroplast Pigments and Chromatographic Analysis, Thirty-second Priestly Lecture, Univ, Park, Pennsylvania (1958). - Marinetti, G. V., and Stotz, E., Biochim. Biophys. Acta, 21, 168 (1956).

${ }^{5}$ Granick, S., J. Biol. Chem., 179, 505 (1949),

\section{Spontaneous Electrical Activity of Cutaneous Receptors in Mormyrids}

Lissmann and Machin ${ }^{1-3}$ have demonstrated that the electric fish, Gymnarchus niloticus, is several thousand times more sensitive to a moving electrostatic charge or a moving magnet than are other fish. The electric receptors were assumed to be the 'mormyromasts' (special cutaneous organs known to exist in Mormyrids and first described by Stendell ${ }^{4}$ ); no experimental proof, however, has been presented to show that the electric stimuli indeed act on these organs.

In 1959, while examining the electrical behaviour of very young Mormyrids (Mormyrops nigricans), the very feeble discharge of which necessitates the use of strong amplification, I observed that the receiving electrodes dipped into the water and in contact with the fish captured rhythmic electric signals of relatively high frequency ( 300 impulses/sec.). The spontaneous electric discharge, generated by tho elcctric organs of tho fish, did not, in any way, affect the characteristics of these signals (Fig. $1 A$ ).

In 1961 these experiments were repeated: previous results were confirmod, and it could be dofinitely proved that on the skin of Mormyrids electric phenomena of different characteristics and location can be found. Briefly described they are as follows: 